\title{
The association between body composition and self-reported co-morbidity in subjects with chronic obstructive pulmonary disease
}

Erica P. A. Rutten ${ }^{1 *}$, Per S. Bakke ${ }^{2}$, Sreekumar G. Pillai ${ }^{3}$, Scott Wagers ${ }^{1}$, Thomas B. Grydeland ${ }^{2}$, Amund Gulsvik ${ }^{2}$, Emiel F. M. Wouters ${ }^{1,4}$

\author{
${ }^{1}$ Center of Expertise for Chronic Organ Failure (Ciro), Horn, The Netherlands \\ ${ }^{2}$ Section of Thoracic Medicine, Institute of Medicine, University of Bergen, Bergen, Norway \\ ${ }^{3}$ Genetics, GlaxoSmithKline R\&D, Raleigh, USA \\ ${ }^{4}$ Department of Respiratory Medicine, Maastricht, The Netherlands \\ Email: *ericarutten@ciro-horn.nl
}

Received 27 February 2012; revised 19 April 2012; accepted 30 April 2012

\begin{abstract}
Background: Differences in body composition are extensively investigated in subjects with COPD as low muscle mass was independently associated with increased morbidity and mortality. Also cardio-vascular co-morbidity is often reported in COPD and the contribution of fat mass in COPD related co-morbidity is gaining interest. We hypothesized that the prevalence of low muscle mass and high fat mass is higher in subjects with COPD compared to a group of current and former smokers without COPD, which result in higher reported cardiovascular co-morbidity in the COPD group. Methods: In 954 subjects with COPD and 955 subjects without COPD, body composition was assessed by bio-electrical impedance analysis and information on self-reported co-morbidity was collected. Participants were stratified for low fat free mass index and high fat mass index (resp. fat free mass index $<10^{\text {th }}$ percentile and fat mass index $>50^{\text {th }}$ percentile of the subjects without COPD). Results: Subjects with COPD were more likely to have low fat free mass index than current and former smokers without COPD. The prevalence of high fat mass index was comparable between the groups. The percentage of self-reported co-morbidity was higher in subjects with COPD, but only reports of myocardial infarction were disease specific. Conclusion: Low fat free mass index was more common in COPD, but the prevalence of high fat mass index was comparable between subjects with and without COPD. Nevertheless, subjects with COPD reported more myocardial infarction, implying that other factors than the amount of fat mass are involved in the increased co-morbidity in COPD.
\end{abstract}

\footnotetext{
${ }^{*}$ Corresponding author.
}

Keywords: Co-Morbidity; Fat Free Mass; Fat Mass

\section{INTRODUCTION}

It is currently accepted that COPD is a heterogeneous disease with a high prevalence of co-morbidity such as cardiovascular disease and diabetes mellitus type II $[1,2]$. Concerning the systemic manifestation of COPD, research focused mainly on low skeletal muscle mass, as it was associated with decreased quality of life [3], exercise intolerance and increased mortality risk [4]. Previous reports have shown that the prevalence of low skeletal muscle mass is common in subjects with COPD, varying from about $11 \%$ in moderate to severe outpatients [5] to about $25 \%-35 \%$ in a large Danish cohort [6], depending on the cut-offs used and on the investigated population. It is believed that the prevalence of low muscle mass is higher in subjects with COPD compared to healthy age matched subjects, but corroborating research is limited. Only recently, it is shown from the Health ABC study that the lean mass in subjects with obstructive lung disease was lower compared to formerly and never smoking controls, but was not different than current smoking controls [7].

On the other hand, the contribution of the fat mass in the systemic manifestation of COPD is yet inconclusive, as metabolic abnormalities were seen in obese subjects with COPD [8] on one hand, but the involvement of the adipose tissue in the systemic inflammation in COPD could not be proven [9]. Nevertheless, cardio-vascular co-morbidity is related to (abdominal) fat mass in the healthy [10], and an increased prevalence of cardiovascular co-morbidity in COPD is reported [11]. In contrast, the report of the Health $\mathrm{ABC}$ study showed lower fat mass in subjects with obstructive lung disease compared 
to formerly and never smokers, but no difference compared to current smoking controls [7].

In the present study, body composition and reports of cardiovascular co-morbidities and diabetes mellitus type II were measured in a large cohort of subjects with COPD and a cohort of current and former smokers without COPD. We hypothesized that there is a higher prevalence of low skeletal muscle mass in subjects with COPD compared to those without COPD when directly compared with low skeletal muscle mass being defined as a fat free mass index (FFMI, fat free mass/length ${ }^{2}$ ) that is less than $10 \%$ of the control population. In addition, the prevalence of high fat mass index is defined as a fat mass index (FMI, fat mass/length ${ }^{2}$ ) that is more than $50 \%$ of the control population, and was associated with the percentage of self-reported co-morbidity.

\section{METHOD}

Details of the sampling and population characteristics are given elsewhere [12-16]. Briefly, the study comprised 954 clinically stable COPD cases according to the American Thoracic Society (ATS) guidelines [17] and 955 control subjects without COPD. Enrolment criteria were: 1) Self-reported Caucasian; 2) Age above 40;3) Current or former smoker with at least 2.5 pack years of smoking history; and 4) No $\alpha_{1}$-antitrypsin deficiency. The medical ethical committee approved the study and all subjects obtained written informed consent.

Subjects underwent spirometry according to ATS standards, using a Vitalograph 2160 Spirometer before and after bronchodilation with $400 \mu \mathrm{g}$ of salbutamol. Local reference values for forced expiratory volume in one second $\left(\mathrm{FEV}_{1}\right)$ and forced expiratory vital capacity (FVC) were used [13]. COPD cases had a post-bronchodilatory $\mathrm{FEV}_{1 /}$ FVC-ratio $<0.70$ and an $\mathrm{FEV}_{1}<80 \%$ of predicted. Controls had a post-bronchodilatory $\mathrm{FEV}_{1} / \mathrm{FVC}$-ratio $>$ 0.70 and an $\mathrm{FEV}_{1}>80 \%$ of predicted. The prevalence or absence of cardiovascular co-morbidities (myocardial infarction or angina, high cholesterol, hypertension) and diabetes mellitus type II (DM type II) was assessed by a self-reported questionnaire.

After overnight fast, body height and weight were measured to the nearest $0.1 \mathrm{~cm}$ and $0.1 \mathrm{~kg}$ respectively. Whole body impedance (expressed in $\Omega$ ) was measured using the bio-electrical impedance method (BIA, Bodys$\left.\operatorname{tat}^{(\mathbb{R}}\right)$. Because of the good intermethod agreement between the formula by Dey et al. for healthy elderly [18] and Rutten et al. for subjects with COPD [19], these formulas were used to calculate FFM in the subjects without and with COPD respectively. Fat mass (FM) was calculated by body weight minus FFM. FFMI and FMI were calculated as respectively FFM and FM divided by height ${ }^{2}$. Since no consistency consists yet in the cut-offs to define low FFMI or high FMI, these cut-offs were defined according to respectively FFMI $<$ the $10^{\text {th }}$ percentile and FMI $>$ the $50^{\text {th }}$ percentile of the subjects without COPD (Table 1).

\section{Statistics}

All data were normally distributed and expressed as mean \pm standard deviation (SD). Differences between the two groups were tested using the unpaired Student's $t$-test. Presence of low FFMI, high FMI and reports of co-morbidities were evaluated in the subjects with COPD and those without COPD, and tested by the Pearson's chi $^{2}$-test. Binary logistic regression analyses were performed with low FFMI and high FMI as dependent variables and sex, age, pack years and disease status (COPD vs. non-COPD) as independent variables. Similar analyses were performed on the co-morbidities as dependent variables and the following independent variables: disease status, sex, age, pack years, FFM and FM. In case disease state was a significant determinant, the binary logistic regression was performed for the subjects with and without COPD separately. Analyses were performed using Statistical Package for the Social Sciences (SPSS) version 15.01 for Windows ${ }^{\circledR}$. A p-value $<0.05$ is considered statistically significant.

\section{RESULTS}

General characteristics of the study subjects are presented in Table 2. Men as well as women without COPD

Table 1. Percentiles of the FFMI and FMI in the study group.

\begin{tabular}{ccc}
\hline & $10^{\text {th }}$ percentile & $50^{\text {th }}$ percentile \\
\hline FFMI $\left(\mathrm{kg} / \mathrm{m}^{2}\right)$ & & \\
Subjects without COPD & & 19.2 \\
Men & $\mathbf{1 7 . 5}$ & 16.6 \\
Women & $\mathbf{1 5 . 0}$ & \\
Subjects with COPD & & 18.6 \\
Men & 16.5 & 15.6 \\
Women & 13.6 & \\
FMI (kg/m $\left.{ }^{2}\right)$ & & \\
Subjects without COPD & & $\mathbf{7 . 6}$ \\
Men & 4.7 & $\mathbf{8 . 6}$ \\
Women & 5.3 & 7.0 \\
Subjects with COPD & & 8.8 \\
Men & 3.5 & \\
Women & 4.7 &
\end{tabular}

The $10^{\text {th }}$ percentile of the FFMI and $50^{\text {th }}$ percentile of the FMI (bold) in subjects without COPD is used as cut-offs for resp. low FFMI and high FMI. 
Table 2. General characteristics of the study participants.

\begin{tabular}{ccccc}
\hline & \multicolumn{2}{c}{ Subjects without COPD } & \multicolumn{2}{c}{ Subjects with COPD } \\
\cline { 2 - 5 } & Men & Women & Men & Women \\
\hline Amount, $\mathrm{n}$ & 479 & 476 & 583 & 371 \\
Age, y & $56.3 \pm 9.9$ & $54.8 \pm 9.4$ & $66.2 \pm 10.2^{*}$ & $64.4 \pm 9.8^{* \dagger}$ \\
FEV1, \% pred & $94.4 \pm 8.9$ & $95.4 \pm 9.2$ & $51.2 \pm 17.8^{*}$ & $50.3 \pm 16.7^{*}$ \\
FEV1/FVC & $0.79 \pm 0.04$ & $0.79 \pm 0.04$ & $0.51 \pm 0.13^{*}$ & $0.53 \pm 0.13^{*}$ \\
Pack years, y & $21.0 \pm 14.4$ & $17.0 \pm 11.6^{\dagger}$ & $35.2 \pm 19.0^{*}$ & $26.8 \pm 15.3^{* \dagger}$ \\
Weight, kg & $86.0 \pm 12.7$ & $71.4 \pm 13.1^{\dagger}$ & $78.8 \pm 15.4^{*}$ & $66.1 \pm 15.8^{* \dagger}$ \\
Height, cm & $178.1 \pm 6.8$ & $165.6 \pm 5.6^{\dagger}$ & $175.1 \pm 6.7^{*}$ & $162.1 \pm 5.9^{* \dagger}$ \\
BMI, kg/m ${ }^{2}$ & $27.1 \pm 3.4$ & $26.0 \pm 4.5^{\dagger}$ & $25.6 \pm 4.4^{*}$ & $25.1 \pm 5.8$ \\
FFM, kg & $61.4 \pm 6.2$ & $46.1 \pm 4.9^{\dagger}$ & $57.3 \pm 7.1^{*}$ & $41.9 \pm 6.2^{* \dagger}$ \\
FFMI, kg/m ${ }^{2}$ & $19.4 \pm 1.6$ & $16.8 \pm 1.7^{\dagger}$ & $18.6 \pm 1.8^{*}$ & $15.9 \pm 2.0^{* \dagger}$ \\
FMI, kg/m ${ }^{2}$ & $7.7 \pm 2.5$ & $9.2 \pm 3.5^{\dagger}$ & $7.0 \pm 2.8^{*}$ & $9.2 \pm 3.9^{\dagger}$ \\
\hline
\end{tabular}

Data are mean \pm SD. Significant differences: with the subjects without COPD: ${ }^{*} \mathrm{p}<0.01$; with male counterparts: ${ }^{\dagger} \mathrm{p}<0.01$. Abbreviations: FEV1: forced expiratory volume in one second, FVC: forced expiratory vital capacity, FEV1/FVC: tiffeneau index, BMI: body mass index, FFM: fat-free mass, FFMI: fat-free mass index, FMI: fat mass index.

were significantly younger than the subjects with COPD. In addition, the subjects without COPD were taller and had higher weight, BMI, FFM, FFMI and FMI compared to the subjects with COPD. The amount of pack years is higher and the lung function parameters were lower in the subjects with COPD. Although the women with COPD had significantly lower amount of pack years compared to their male peers, they had the same degree of lung function impairment.

The percentage low FFMI and high FMI in subjects with and without COPD is presented in Figure 1. In both sexes, the percentage low FFMI was higher in subjects with COPD compared to those without COPD. The percentage high FMI was not different between women with and without COPD, but was lower in men with COPD compared to men without COPD. Figure 2 represents the percentage of low FFMI and high FMI in men and women with COPD after stratification for BMI. A BMI of $25 \mathrm{~kg} / \mathrm{m}^{2}$ was discriminative for low FFMI, but not for high FMI.

The logistic regression analysis to find determining factors for low FFMI and high FMI is presented in Table 3. Subjects with COPD were more likely to have low FFMI than the subjects without COPD (OR: 3.5, 95\% confidence intervals (CI): 2.33 - 5.27). As disease status is a significant determinant for low FFMI, the binary logistic regression is performed in subjects with and without COPD separately (Table 4). In the subjects without COPD, none of the factors remained significant,

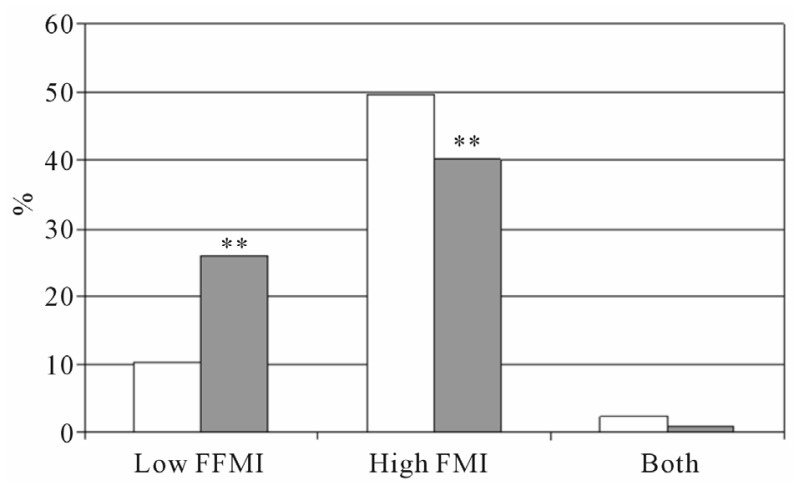

(a)

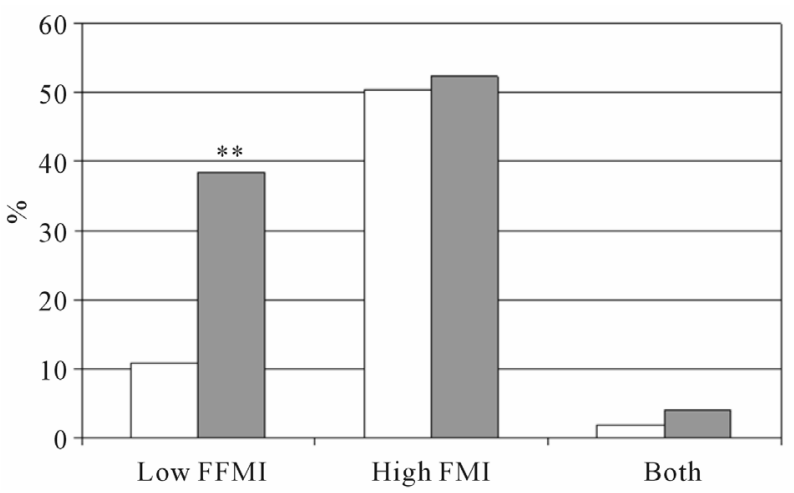

(b)

Figure 1. Percentage of low FFMI, high FMI and both low FFMI and high FMI. Men (a) and women (b) with and without COPD; white bars indicate subjects without COPD, grey bars indicate subjects with COPD. Significances: $* * p<0.01$ vs. subjects without COPD.

Table 3. Binary logistic regression analyses with low fat free mass index and high fat mass index as dependent variables.

\begin{tabular}{|c|c|c|c|c|}
\hline & B & Odds-ratio & $95 \%$ CI & p-value \\
\hline \multicolumn{5}{|c|}{ Low fat free mass index } \\
\hline Status $(1=\mathrm{COPD})$ & 1.25 & 3.50 & $2.33-5.27$ & $<0.01$ \\
\hline $\operatorname{Sex}(1=\operatorname{men})$ & -0.43 & 0.65 & $0.46-0.93$ & 0.02 \\
\hline Age & -0.01 & 0.99 & $0.98-1.02$ & 0.88 \\
\hline Pack years & 0.01 & 1.00 & $0.99-1.01$ & 0.82 \\
\hline \multicolumn{5}{|c|}{ High fat mass index } \\
\hline Status $(1=$ COPD $)$ & -0.18 & 0.84 & $0.62-1.12$ & 0.24 \\
\hline $\operatorname{Sex}(1=$ men $)$ & -0.18 & 0.83 & $0.64-1.09$ & 0.18 \\
\hline Age & 0.01 & 1.00 & $0.99-1.02$ & 0.90 \\
\hline Pack years & 0.01 & 1.01 & $1.00-1.01$ & 0.17 \\
\hline
\end{tabular}

while in the subject with COPD, women were more likely to have low FFMI compared to men (OR: 0.51, $95 \%$ CI: 0.33 - 0.79). Regarding high FMI, there were no significant co-variates.

As the subjects without COPD were younger than the 

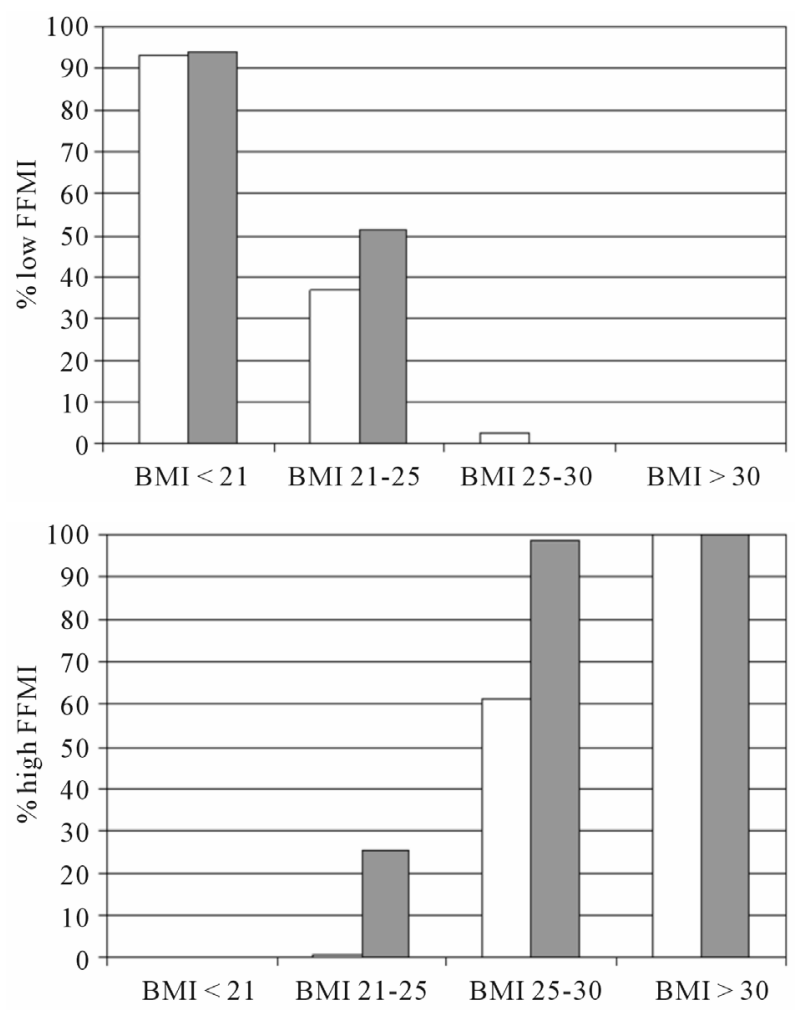

Figure 2. The percentage of low FFMI and high FMI in subjects with COPD after stratification for BMI. White bars indicate men, grey bars indicate men.

Table 4. Binary logistic regression analyses with low fat free mass index as dependent variable in the subjects with and without COPD separately.

\begin{tabular}{ccccc}
\hline & B & Odds-ratio & $\mathbf{9 5 \%}$ CI & p-value \\
\hline \multicolumn{2}{l}{ Subjects without COPD } & & & \\
Sex $(1=$ men $)$ & 0.01 & 1.01 & $0.55-1.84$ & 0.98 \\
Age & -0.02 & 0.98 & $0.95-1.01$ & 0.27 \\
Pack years & -0.01 & 1.00 & $0.97-1.02$ & 0.76 \\
Subjects with COPD & & & \\
Sex (1 = men) & -0.67 & 0.51 & $0.33-0.79$ & $<0.01$ \\
Age & 0.01 & 1.01 & $0.99-1.03$ & 0.49 \\
Pack years & 0.01 & 1.01 & $1.00-1.02$ & 0.56 \\
\hline
\end{tabular}

subjects with COPD, which could affect our results concerning the prevalence of low fat free mass index, we performed a sub-analyses after matching the groups for age: the authors selected a subgroup of subjects with the age between 55 and 65 years. Amount of subjects and mean age of the subjects without COPD was: men: $\mathrm{n}=$ 142 , mean age: $59.5 \mathrm{y} \pm 2.6 \mathrm{y}$, women: $\mathrm{n}=133$, mean age $=59.3 \mathrm{y} \pm 2.9 \mathrm{y}$ and of the subjects with COPD: men: $\mathrm{n}=173$, mean age $=60.1 \pm 2.9 \mathrm{y}$, women: $\mathrm{n}=126$, mean age: $59.6 \mathrm{y} \pm 2.8 \mathrm{y}$. The prevalence of low FFMI and high FMI is shown in Figure 3, and are comparable with the whole group.

The percentage of self-reported co-morbidity in subjects with COPD and those without COPD is shown in Figure 4 for men and women separately. Both men and women with COPD reported more myocardial infarction and hypertension compared to their counterparts. Women with COPD reported also more hypercholesterol compared to those without COPD. Performing binary logistic regression analyses with the self-reported co-morbidities separately as dependent variable, age and FM were significant determinants for all co-morbidities (Table 5). In addition, subjects with COPD were more likely to report myocardial infarction than the subjects without COPD (OR: 1.98, 95\%CI: 1.18 - 3.30). Therefore, the binary logistic regression was performed for subjects with and without COPD separately (Table 6). Age and fat mass remained in the model for both subjects with and without COPD. Among the subjects without COPD, men were more likely to report myocardial infarction (OR: 10.18, 95\%CI: $1.63-63.63$ ).

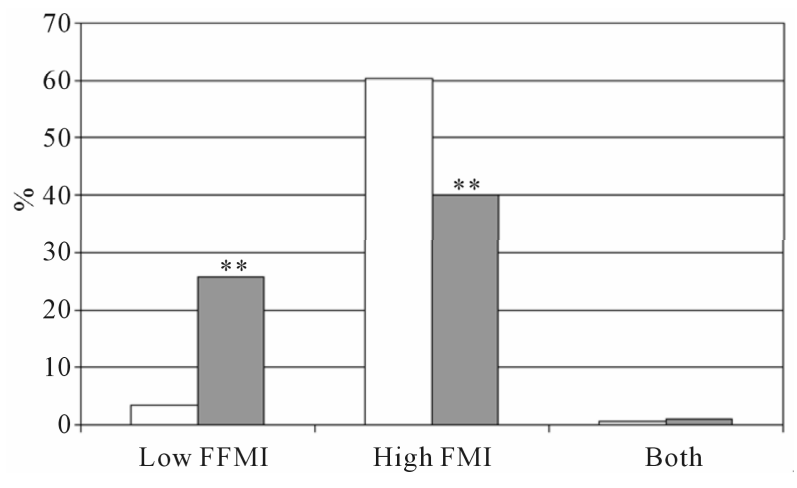

(a)

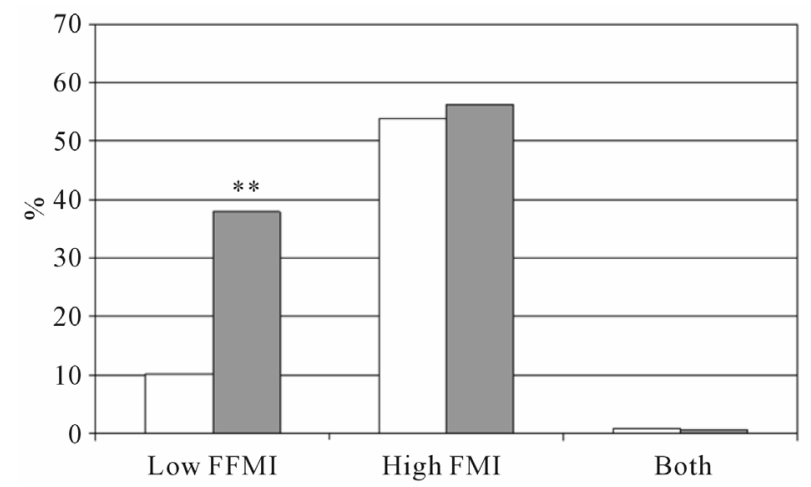

(b)

Figure 3. Percentage of low FFMI, high FMI and both low FFMI and high FMI in subjects with and without COPD after matching for age. (a) Men; (b) Women, white bars indicate subjects without COPD, grey bars indicate subjects with COPD. Significances: ${ }^{* *} \mathrm{p}<0.01$ vs. subjects without COPD. 


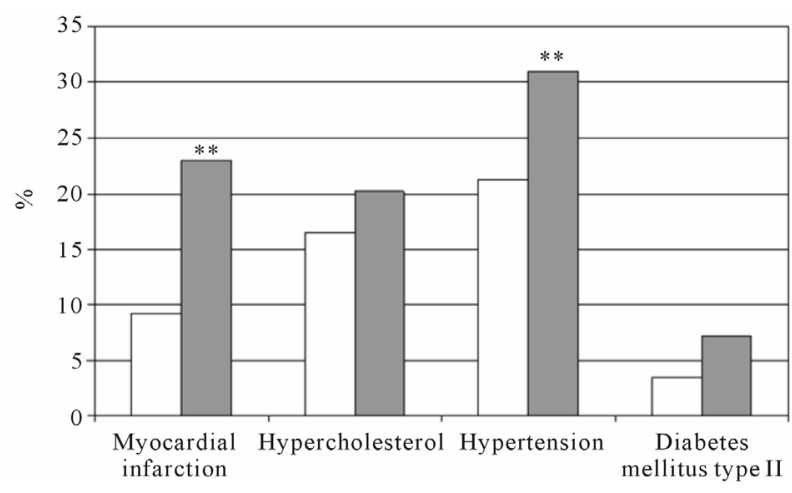

(a)

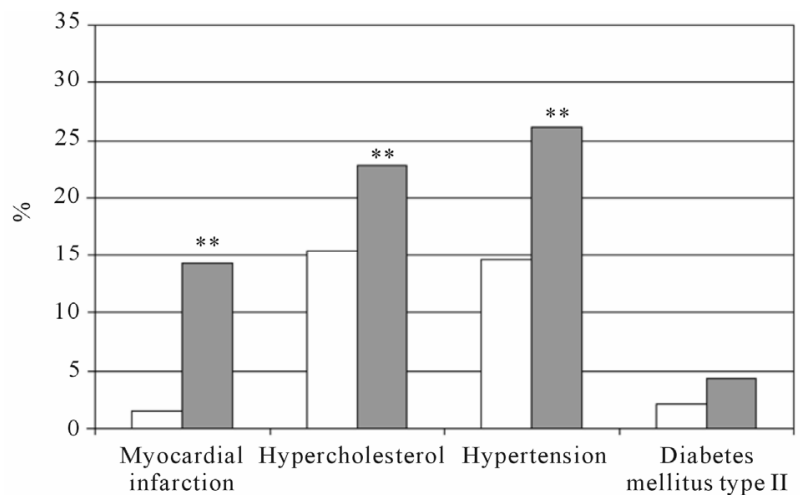

(b)

Figure 4. The percentage of self-reported cardiovascular comorbidities and diabetes mellitus type II. Man (a) and women (b) with and without COPD; white bars indicate subjects without COPD, grey bars indicate subjects with COPD. Significances: $* * \mathrm{p}<0.01$ vs. subjects without COPD.

\section{DISCUSSION}

The present study confirms that low FFMI is more prevalent in a large group of subjects with moderate to severe COPD when compared to current and former smokers without COPD, independent of sex and age. In addition, the prevalence of low FFMI is higher in women with COPD compared to men with COPD. Although subjects with COPD reported more myocardial infarction, high FMI was not disease specific. This implies that other factors than the amount of fat mass are involved in the co-morbid manifestation of COPD.

Previous cross-sectional studies imply associations between low muscle mass and functional impairment [20], and worse health state [3]. Therefore, there was a rationale to define a low fat free mass index in order to be able to screen patients vulnerable for worse morbidity. Up to the present, objective determined cut-offs to define low FFMI in COPD are lacking. Therefore, in the present study, the $10^{\text {th }}$ percentile of the FFMI in the cohort without COPD was used as a cut-off for defining low FFMI. These cut-offs (see Table $1 ; 17.5 \mathrm{~kg} / \mathrm{m}^{2}$ for men and 15.0 $\mathrm{kg} / \mathrm{m}^{2}$ for women) are in the same order as the cut-offs
Table 5. Binary logistic regression analyses with cardiovascular co-morbidity and diabetes mellitus type II as dependent variable.

\begin{tabular}{|c|c|c|c|c|}
\hline & B & Odds-ratio & $95 \%$ CI & p-value \\
\hline \multicolumn{5}{|c|}{ Myocardial infarction } \\
\hline Status $(1=$ COPD $)$ & 0.68 & 1.98 & $1.18-3.30$ & $<0.01$ \\
\hline $\operatorname{Sex}(1=\operatorname{men})$ & 1.42 & 4.15 & $1.55-11.13$ & $<0.01$ \\
\hline Age & 0.09 & 1.09 & $1.07-1.12$ & $<0.01$ \\
\hline Pack years & 0.01 & 1.00 & $0.99-1.01$ & 0.98 \\
\hline Fat free mass & -0.04 & 1.01 & $0.90-1.01$ & 0.10 \\
\hline Fat mass & 0.05 & 1.05 & $1.02-1.09$ & $<0.01$ \\
\hline \multicolumn{5}{|l|}{ High cholesterol } \\
\hline Status $(1=$ COPD $)$ & -0.06 & 0.95 & $0.64-1.39$ & 0.78 \\
\hline $\operatorname{Sex}(1=$ men $)$ & -0.29 & 0.75 & $0.37-1.53$ & 0.43 \\
\hline Age & 0.05 & 1.05 & $1.03-1.07$ & $<0.01$ \\
\hline Pack years & 0.01 & 1.01 & $1.00-1.02$ & 0.03 \\
\hline Fat free mass & 0.01 & 1.01 & $0.97-1.04$ & 0.84 \\
\hline Fat mass & 0.04 & 1.04 & $1.01-1.06$ & $<0.01$ \\
\hline \multicolumn{5}{|l|}{ Hypertension } \\
\hline Status $(1=$ COPD $)$ & 0.12 & 1.13 & $0.78-1.63$ & 0.53 \\
\hline $\operatorname{Sex}(1=$ men $)$ & 0.09 & 1.09 & $0.55-2.19$ & 0.81 \\
\hline Age & 0.06 & 1.07 & $1.05-1.09$ & $<0.01$ \\
\hline Pack years & 0.01 & 1.01 & $1.00-1.02$ & 0.25 \\
\hline Fat free mass & 0.01 & 1.01 & $0.97-1.05$ & 0.60 \\
\hline Fat mass & 0.05 & 1.05 & $1.02-1.07$ & 0.00 \\
\hline \multicolumn{5}{|c|}{ Diabetes mellitus type II } \\
\hline Status $(1=\mathrm{COPD})$ & 0.62 & 1.86 & $0.84-4.09$ & 0.13 \\
\hline $\operatorname{Sex}(1=\operatorname{men})$ & -0.37 & 0.62 & $0.16-2.97$ & 0.62 \\
\hline Age & 0.06 & 1.06 & $1.02-1.10$ & $<0.01$ \\
\hline Pack years & -0.01 & 0.98 & $0.97-1.01$ & 0.24 \\
\hline Fat free mass & 0.05 & 1.05 & $0.98-1.13$ & 0.16 \\
\hline Fat mass & 0.06 & 1.06 & $1.01-1.11$ & 0.03 \\
\hline
\end{tabular}

proposed by Vestbo et al. $\left(17.1 \mathrm{~kg} / \mathrm{m}^{2}\right.$ for men and 14.6 $\mathrm{kg} / \mathrm{m}^{2}$ for women) [6], supporting the implementation of these cut-offs for the definition of low fat free mass index in clinical practice. Moreover, a BMI of $25 \mathrm{~kg} / \mathrm{m}^{2}$ was discriminative for the presence of low muscle mass in subjects with COPD, indicating that the practical value of body composition assessment for defining low skeletal muscle mass decreases when BMI reaches $25 \mathrm{~kg} / \mathrm{m}^{2}$.

The results of the present study reveal that the likelihood of having low FFMI is higher and the likelihood of having high fat mass index is similar in subjects with COPD compared current and former smokers without 
Table 6. Binary logistic regression analyses with myocardial infarction as dependent in the subjects with and without COPD separately.

\begin{tabular}{|c|c|c|c|c|}
\hline & B & Odds-ratio & $95 \%$ CI & p-value \\
\hline \multicolumn{5}{|c|}{ Subjects without COPD } \\
\hline $\operatorname{Sex}(1=\operatorname{men})$ & 2.32 & 10.18 & $1.63-63.63$ & 0.01 \\
\hline Age & 0.11 & 1.12 & $1.06-1.17$ & $<0.01$ \\
\hline Pack years & 0.02 & 1.02 & $0.99-1.04$ & 0.10 \\
\hline Fat free mass & -0.02 & 0.98 & $0.90-1.07$ & 0.65 \\
\hline Fat mass & 0.06 & 1.06 & $1.01-1.12$ & 0.03 \\
\hline \multicolumn{5}{|c|}{ Subjects with COPD } \\
\hline $\operatorname{Sex}(1=\operatorname{men})$ & 1.09 & 2.97 & $0.81-10.96$ & 0.10 \\
\hline Age & 0.09 & 1.09 & $1.06-1.12$ & $<0.01$ \\
\hline Pack years & -0.01 & 1.00 & $0.98-1.01$ & 0.49 \\
\hline Fat free mass & -0.04 & 0.96 & $0.89-1.03$ & 0.22 \\
\hline Fat mass & 0.05 & 1.05 & $1.01-1.10$ & 0.05 \\
\hline
\end{tabular}

COPD, even after adjustment for age, sex and pack years. A recent report of the Health $\mathrm{ABC}$ study showed no difference in lean mass between subjects with obstructive lung disease and smoking controls, but lower levels compared to formerly and never smoking controls [7]. The same results were seen for fat mass. In addition, the longitudinal data analyses of the Health ABC study reported that the decline in lean mass and fat mass over 8 years was not disease specific. Although the later study had a relatively small number of subjects (150 subjects with obstructive lung disease and 74 smoking controls), this is the first cohort study comparing body composition in subjects with obstructive lung disease with an age matched control group. The consistent finding of a higher prevalence of low FFMI in COPD, even after correction for age, suggests an interaction between the skeletal muscle compartment and the lung disease. It can be hypothesized that low muscle mass develops early in the disease or as a consequence of smoking, but more longitudinal observational research should be performed to unravel this question.

The percentage of high FMI was comparable between women with and without COPD, but was lower in men with COPD compared to men without COPD. In the binary logistic regression, disease state was however no significant determinant for the presence of high fat mass index. The prevalence of high fat mass in relation to gender differences in COPD is scarcely investigated so far. One study evaluated the effect of weight gain on systemic inflammation in subjects with COPD [21]. The results of that study revealed that the positive association between weight gain and the increase in plasma CRP concentration was higher in women with COPD compared to men. Another cross-sectional study, found that plasma levels of leptin were higher in obese women with COPD compared to obese control women [22]. These data imply disease specific gender related differences in the metabolic function of fat mass, but they do not give insight in a different amount of fat mass between men and women. Despite a lower percentage of high fat mass index in men with COPD, they reported more myocardial infarction and hypertension than men without COPD. Women with COPD reported also more hypercholesterol than women without COPD. However, disease status remained, besides age and fat mass, only in the model on reports of myocardial infarction. This finding is in line with a study by Sin et al. reporting that COPD per se is associated with higher cardio-vascular risk (11). Fat mass was a significant determinant in all models for cardiovascular co-morbidity and diabetes mellitus type II, implying that fat mass is involved in the cardiovascular pathology, irrespective of the disease state.

There are some methodological considerations that need to be taken into account when interpreting the results of this study. The design of the present study is cross-sectional and not longitudinal, thus the results cannot provide insight into changes in body composition over time. Furthermore, the authors are aware that a self-reported questionnaire for cardiovascular co-morbidity and diabetes mellitus type II can underestimate the real presence of these co-morbidities. Nevertheless, higher reports are shown in the subjects with COPD, likely due to the large amount of subjects included, which is a strength of the study. Finally, the subjects without COPD were about 10 year younger than the subjects with COPD, which could influence the findings on body composition. However, age was no significant determinant in the binary logistic regression analyses, and the results remained after matching the groups for age. The authors decided to preserve the total study group instead of a subgroup matched for age for the analyses, because it increases the power of the study.

The present study confirms that prevalence of low fat free mass index is higher in subjects with COPD compared to current and former subjects without COPD. The prevalence of high fat mass index was comparable between the subjects with and without COPD, implying that other factors than the amount of fat mass contribute to the observed higher self-reported myocardial infarction in COPD.

\section{REFERENCES}

[1] Lindberg, A., Larsson, L.G., Ronmark, E. and Lundback, B. (2011) Co-morbidity in mild-to-moderate COPD: Com- 
parison to normal and restrictive lung function. Chronic Obstructive Pulmonary Disease, 8, 421-428. doi:10.3109/15412555.2011.629858

[2] Agusti, A., Calverley, P.M., Celli, B., Coxson, H.O., Edwards, L.D., Lomas, D.A., et al. (2010) Characterisation of COPD heterogeneity in the ECLIPSE cohort. Respiratory Research, 11, 122.

[3] Mostert, R., Goris, A., Weling-Scheepers, C., Wouters, E.F. and Schols, A.M. (2000) Tissue depletion and health related quality of life in patients with chronic obstructive pulmonary disease. Respiratory Medicine, 2000, 94, 859867. doi:10.1053/rmed.2000.0829

[4] Schols, A.M., Broekhuizen, R., Weling-Scheepers, C.A. and Wouters, E.F. (2005) Body composition and mortality in chronic obstructive pulmonary disease. The American Journal of Clinical Nutrition, 82, 53-59.

[5] Vermeeren, M.A., Creutzberg, E.C., Schols, A.M., Postma, D.S., Pieters, W.R., Roldaan, A.C., et al. (2006) Prevalence of nutritional depletion in a large out-patient population of patients with COPD. Respiratory Medicine, 100, 1349-1355. doi:10.1016/j.rmed.2005.11.023

[6] Vestbo, J., Prescott, E., Almdal, T., Dahl, M., Nordestgaard, B.G., Andersen, T., et al. (2006) Body mass, fatfree body mass, and prognosis in patients with chronic obstructive pulmonary disease from a random population sample: Findings from the Copenhagen City Heart Study. American Journal of Respiratory and Critical Care Medicine, 173, 79-83. doi:10.1164/rccm.200505-969OC

[7] Van Den Borst, B., Koster, A., Yu, B., Gosker, H.R., Meibohm, B., Bauer, D.C., et al. (2011) Is age-related decline in lean mass and physical function accelerated by obstructive lung disease or smoking? Thorax, 66, 961969. doi:10.1136/thoraxjnl-2011-200010

[8] Poulain, M., Doucet, M., Drapeau, V., Fournier, G., Tremblay, A., Poirier, P., et al. (2008) Metabolic and inflammatory profile in obese patients with chronic obstructive pulmonary disease. Chronic Respiratory Disease, 5, 35-41. doi:10.1177/1479972307087205

[9] Van Den Borst, B., Gosker, H.R., Wesseling, G., De Jager, W., Hellwig, V.A., Snepvangers, F.J., et al. (2011) Low-grade adipose tissue inflammation in patients with mild-to-moderate chronic obstructive pulmonary disease. The American Journal of Clinical Nutrition, 94, 15041512. doi:10.3945/ajen.111.023911

[10] De Luis, D.A., Sagrado, M.G., Conde, R., Aller, R., Izaola, O. and Romero, E. (2007) Circulating adipocytokines in obese nondiabetic patients in relationship with cardiovascular risk factors, anthropometry and restingenergy expenditure. Annals of Nutrition and Metabolism, 51, 416-420. doi:10.1159/000111160

[11] Sin, D.D. and Man, S.F. (2003) Why are patients with chronic obstructive pulmonary disease at increased risk of cardiovascular diseases? The potential role of systemic inflammation in chronic obstructive pulmonary disease. Circulation, 107, 1514-1519. doi:10.1161/01.CIR.0000056767.69054.B3

[12] Zhu, G., Warren, L., Aponte, J., Gulsvik, A., Bakke, P.,
Anderson, W.H., et al. (2007) The SERPINE2 gene is associated with chronic obstructive pulmonary disease in two large populations. American Journal of Respiratory and Critical Care Medicine, 176, 167-173. doi:10.1164/rccm.200611-17230C

[13] Gulsvik, A., Tosteson, T., Bakke, P., Humerfelt, S., Weiss, S.T. and Speizer, F.E. (2001) Expiratory and inspiratory forced vital capacity and one-second forced volume in asymptomatic never-smokers in Norway. Clinical Physiology, 21, 648-660. doi:10.1046/j.1365-2281.2001.00377.x

[14] Kauffmann, F. (2007) SERPINE2 and COPD. American Journal of Respiratory and Critical Care Medicine, 176, 725-726.

[15] Eagan, T.M., Gulsvik, A., Eide, G.E. and Bakke, P.S. (2004) Remission of respiratory symptoms by smoking and occupational exposure in a cohort study. European Respiratory Journal, 23, 589-594. doi:10.1183/09031936.04.00041204

[16] Brogger, J., Eagan, T., Eide, G.E., Bakke, P. and Gulsvik, A. (2004) Bias in retrospective studies of trends in asthma incidence. European Respiratory Journal, 23, 281286. doi:10.1183/09031936.03.00041103

[17] Rabe, K.F., Beghe, B., Luppi, F. and Fabbri, L.M. (2007) Update in chronic obstructive pulmonary disease 2006. American Journal of Respiratory and Critical Care Medicine, 175, 1222-1232. doi:10.1164/rccm.200704-586UP

[18] Dey, D.K., Bosaeus, I., Lissner, L. and Steen, B. (2003) Body composition estimated by bioelectrical impedance in the Swedish elderly. Development of population-based prediction equation and reference values of fat-free mass and body fat for 70- and 75-y olds. European Journal of Clinical Nutrition, 57, 909-916. doi:10.1038/sj.ejen.1601625

[19] Rutten, E.P.A., Spruit, M.A. and Wouters, E.F.M. (2010) Critical view on diagnosing muscle wasting by single-frequency bio-eletrical impedance in COPD. Respiratory Medicine, 104, 91-98. doi:10.1016/j.rmed.2009.07.004

[20] Gosker, H.R., Kubat, B., Schaart, G., Van Der Vusse, G.J., Wouters, E.F. and Schols, A.M. (2003) Myopathological features in skeletal muscle of patients with chronic obstructive pulmonary disease. European Respiratory Journal, 22, 280-285. doi:10.1183/09031936.03.00012803

[21] Bridevaux, P.O., Gerbase, M.W., Schindler, C., Felber, D.D., Curjuric, I., Dratva, J., et al. (2009) Sex-specific effect of body weight gain on systemic inflammation in subjects with COPD. European Respiratory Journal, 34, 332-339. doi:10.1183/09031936.00162608

[22] Breyer, M.K., Rutten, E.P., Vernooy, J.H., Spruit, M.A., Dentener, M.A., Van Der Kallen, C., et al. (2011) Gender differences in the adipose secretome system in chronic obstructive pulmonary disease (COPD): A pivotal role of leptin. Respiratory Medicine, 105, 1046-1053. doi:10.1016/j.rmed.2011.02.001 